\title{
THE BLOOD-PRESSURE IN PNEUMONIA *
}

\author{
L. H. NEWBURGH, M.D., † and GEORGE R. MINOT, M.D. \\ BOSTON
}

For decades clinicians have believed that many of the grave symptoms and a large number of the deaths in pneumonia were directly due to failure of the circulation. In 1889 Romberg $^{1}$ and his associates studied the problem and reached the conclusion that, while fatal circulatory failure did occur in rabbits inoculated with lethal doses of pneumococci, the failure was not of myocardial origin as had been supposed, but was invariably caused by the exhaustion of the vasomotor center in the bulb.

Since that time physicians have tried to combat the failure of the vasomotor mechanism in pneumonia by administering drugs which would augment the activity of the vasomotor center.

The results have been sufficiently confusing to make a re-investigation desirable. The present communication deals only with the blood-pressure in pneumonia. Other phases of the subject will appear in later papers.

If it be true that grave symptoms and death in pneumonia be caused by failure of the vasomotor apparatus, then it ought to be possible to divide cases of lobar pneumonia into two groups:

1. Those in which the vasomotor apparatus is intact.

2. Those in which the vasomotor apparatus is seriously injured.

In the first group the blood-pressure measurements ought to fall on a curve which does not diverge widely from that for normal individuals. In the second group the blood-pressure curve ought to be strikingly below the normal and to fall still lower as the gravity of the vasomotor disturbance increases. The blood-pressure curve ought to be the most reliable single measure of the state of the circulation in pneumonia, and a definite and exact indicator for our therapeutic efforts.

In 1911 Weigert $^{2}$ studied the blood-pressure in a variety of infectious diseases, including pneumonia, and reviewed the work of the

* Submitted for publication, March 9, 1914.

* From the East Medical Service of the Massachusetts General Hospital.

$\dagger$ Aided by grant from the Council on Pharmacy and Therapeutics of the American Medical Association.

1. Romberg, Pässler, Bruhns and Müller: Experimentelle Untersuchungen über die allgemeine Pathologie der Kreislaufstörung bei acuten Infectionskrankheiten, Arch. f. klin. Med., 1899, 1xiv, 652.

2. Weigert, K.: Ueber das Verhalten des Arteriellen Blutdrucks bei den acuten Infectionskrankheiten, Samml. klin. Vortr. (Volkmann's) Inn. Med.. No. 138 , p. 459. 
earlier observers. He found that the statements of his predecessors were so contradictory that he could draw no conclusions from them. Among his own thirty-five cases there were six deaths. The pressures were not low in these cases. He separated the recoveries into several groups, that is: In six cases there was no effect on pressure. In nine cases the curve showed a gradual progressive fall from 25 to 35 $\mathrm{mm}$. which reached its lowest point, on the average, on the ninth day after the crisis and was unaffected by the crisis. In three cases there were steep falls which bore no relation to the crisis. In the twelve remaining cases the curve showed a progressive rise. In several instances the pressure rose $40 \mathrm{~mm}$. during the crisis. Weigert found that he could not explain these enormous variations on the basis of age, sex, general strength of patient, severity or length of the disease, the extent of dyspnea, the kind or the amount of stimulation. His general conclusion is that one can establish no rule for the bloodpressure curve in pneumonia and that, consequently, blood-pressure readings in pneumonia are of no prognostic value.

In contrast to this view is the statement of G. A. Gibson, ${ }^{3}$ that "a pressure appreciably below the normal in pneumonia is invariably of evil omen and any considerable fall bodes disaster. When the arterial pressure, expressed in mm. $\mathrm{Hg}$ does not fall below the pulserate, expressed in beats per minute, the fact may be taken as of excellent augury, while the converse is equally true. From the work of the last few years in my own wards no fact is more certain than this." This is known as Gibson's rule.

Gordon ${ }^{4}$ confirmed Gibson's statement on the basis of observations of fifteen cases. Unfortunately the data from which Gordon's conclusions are drawn are omitted from his paper.

The blood-pressure in fifteen cases of lobar pneumonia occurring on the East Medical Service of the Massachusetts General Hospital from March 1, 1913, to Dec. 1, 1913, have been studied. The measurements have, as a rule, been made in the middle of the morning and the middle of the afternoon on each patient from entrance until death, or, in the case of recovery, well into the convalescence. All cases in which there was any doubt about the diagnosis and all persons who had any form of chronic cardiovascular disease were excluded. Further than this, there was no selection.

3. Gibson, G. A.: Some Lessons from the Study of the Arterial Pressure, Edinburgh Med. Jour., 1908, n. s., xxiii, 17.

4. That point at which the fourth tone phase passed into the fifth was called the diastolic pressure.

5. Gordon. G. A.: Some Remarks on the Value of Accurate Blood-Pressure Estimation, Edinburgh Med. Jour., n. s., iv, 31. 
All measurements were made by one of us (G. R. M.). The apparatus employed consisted of a graduated U-tube containing mercury attached to a broad arm-band. All the readings were made by the auscultatory method. Not only the systolic has been measured, but also the diastolic ${ }^{4}$ and pulse-pressure. It was hoped in this way to gain more information than could be obtained by studying merely the systolic pressure.

There were five deaths in the group of fifteen cases. The cases of recovery were roughly divided into two groups, mild and severe according to the general clinical impression they made, regardless of the blood-pressure.

Figure 1 presents a summary of the blood-pressure data. The abscissae represent blood-pressure in millimeters of mercury. The space between each two ordinates represents a day of twenty-four hours. The last day on the chart is the day of the crisis or the day of death as the case may be. The upper and lower unbroken lines are the average of the systolic and diastolic pressures in the fatal cases. The averages were calculated in each case by placing all the measurements obtained during the last day of life in the last column on the right of the chart; the measurements of the next to the last day of life in the next to last column of the chart and so on until we had reached the day of entrance. In this way composite data for similar periods of the disease are obtained. The individual measurements for the fatal cases are indicated by $\mathrm{X}$. The heavy broken lines represent the averages of the systolic and diastolic pressures of the persons who recovered. In this group all the measurements obtained on the critical day were placed in the last column of the chart, and all measurements obtained on the day preceding the crisis in the next to last column of the chart. The individual measurements are indicated by dots and the outer limits of the field by the fine broken line.

It is apparent that the systolic pressure in the fatal cases was continuously above the systolic pressure of the persons who recovered. We are, consequently, unable to accept Gibson's dictum that "a pressure appreciably below the normal is invariably of evil omen." It will be noted that the diastolic pressure of the recoveries shows a slight but progressive fall while the systolic pressure remains very nearly level. This results in an increasing pulse-pressure as the crisis is approached. The fatal cases show a slight tendency in the opposite direction. But the difference is small. By consulting the accompanying table it will be seen that the average of the pulse-pressures on the day of death in the fatal cases is $6 \mathrm{~mm}$. less than the average of the pulse-pressures of the recoveries on the critical day. 


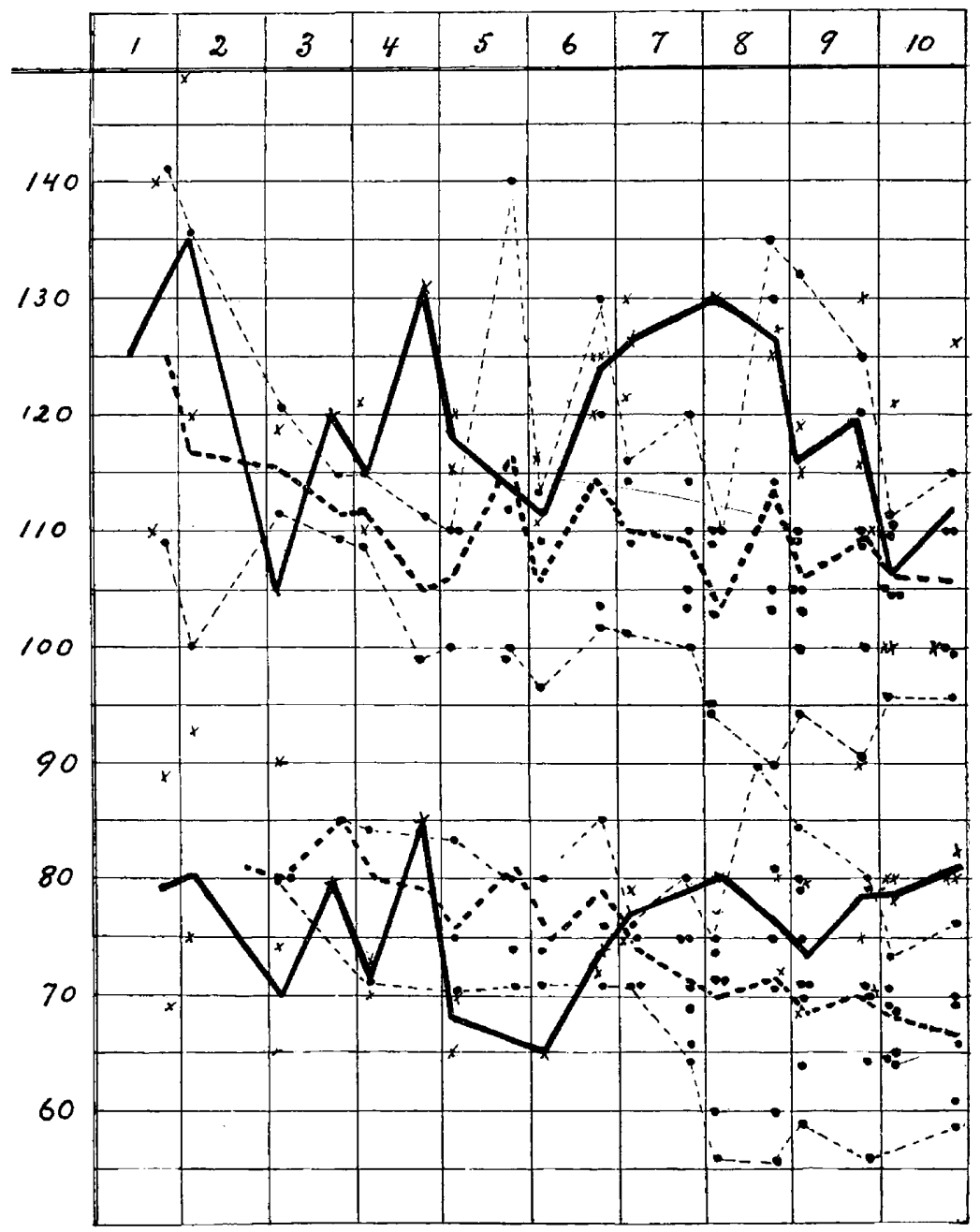

Fig. 1.-Presents a summary of the blood-pressure data from Massachusetts General Hospital cases. The abscissae represent blood-pressure in millimeters of mercury. The space between each two ordinates represents a day of twentyfour hours. The last day on the chart is the day of the crisis or the day of death as the case may be. The upper and lower unbroken lines are the average of the systolic and diastolic pressures in the fatal cases. The averages were calculated by placing all the measurements obtained during the last day of life in each case in the last column on the right of the chart; the measurements of the next to last day of life in the next to last column of the chart and so on until we had reached the day of entrance. In this way composite data for similar periods of the disease are obtained. The individual measurements for the fatal cases are indicated by $X$. The heavy broken lines represent the averages of the systolic and diastolic pressures of the persons who recovered. In this group all the measurements obtained on the critical day were placed in the last column of the chart. All measurements obtained on the day preceding the crisis were placed in the next to last column of the chart. The individual measurements are indicated by dots and the outer limits of the field by the fine broken line. 
The table shows further that while the smallest pulse-pressures$20 \mathrm{~mm}$.- occurred in two fatal cases, the largest pulse-pressure of the series was found also in a fatal case.

In Figure 2, two charts of temperature, pulse and respiration are reproduced to show that death may occur with a small or a large pulse-pressure, with a rising or a falling systolic pressure, with a systolic pressure above or below the pulse.

The Blood-Pressure in Pneumonia: Readings on Day of Crisis or Day OF Drath

\begin{tabular}{|c|c|c|c|}
\hline Type & $\begin{array}{l}\text { Systolic } \\
\text { Pressure }\end{array}$ & $\begin{array}{l}\text { Diastolic } \\
\text { Pressure }\end{array}$ & $\begin{array}{l}\text { Pulse- } \\
\text { Pressure }\end{array}$ \\
\hline 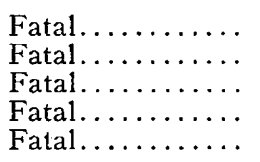 & $\begin{array}{l}120-125 \\
125 \\
100 \\
100 \\
105\end{array}$ & $\begin{array}{c}70 \\
80 \\
80 \\
80 \\
70-75\end{array}$ & $\begin{array}{c}50 \\
45 \\
20 \\
20 \\
30-35\end{array}$ \\
\hline Average......... & 110 & 77 & 34 \\
\hline $\begin{array}{l}\text { Severe........... } \\
\text { Severe........... } \\
\text { Severe.......... }\end{array}$ & $\begin{array}{c}120 \\
110-125 \\
110\end{array}$ & $\begin{array}{c}80 \\
70-80 \\
70\end{array}$ & $\begin{array}{c}40 \\
40-50 \\
40\end{array}$ \\
\hline Average......... & 116 & 75 & 42 \\
\hline 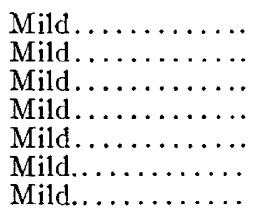 & $\begin{array}{l}100 \\
110 \\
110 \\
105 \\
100 \\
115 \\
102\end{array}$ & $\begin{array}{l}70 \\
70 \\
80 \\
65 \\
60 \\
70 \\
63\end{array}$ & $\begin{array}{l}30 \\
40 \\
30 \\
40 \\
40 \\
45 \\
40\end{array}$ \\
\hline Average........ & 106 & 68 & 38 \\
\hline
\end{tabular}

Gibson has stated that "when the arterial pressure, expressed in $\mathrm{mm}$. $\mathrm{Hg}$, does not fall below the pulse-rate expressed in beats per minute, the fact may be taken as of excellent augury, while the converse is equally true." An analysis of the cases fails to justify this statement. Among five fatal cases the systolic pressure fell above the pulse twice-an error of 40 per cent. Among ten recoveries the systolic pressure failed to fall above the pulse five times-an error of 50 per cent.

Owing to the great kindness of Dr. L. F. Barker and Dr. W. S. Thayer, we have had access to the records of cases of pneumonia treated at the Johns Hopkins Hospital. For purposes of study the last fourteen deaths and the last sixteen recoveries from lobar pneumonia have been selected. Cases of children, all cases in which the 
records were incomplete and also all in which there was any doubt about the diagnosis have been excluded. The pressure was measured in a routine way, two or more times daily by a number of persons; but, as a rule, the same person made all or nearly all the measurements on any single case. Systolic pressure only was recorded.

The course of the systolic pressure in the fatal cases has been compared with that of the persons who recovered, using the same method

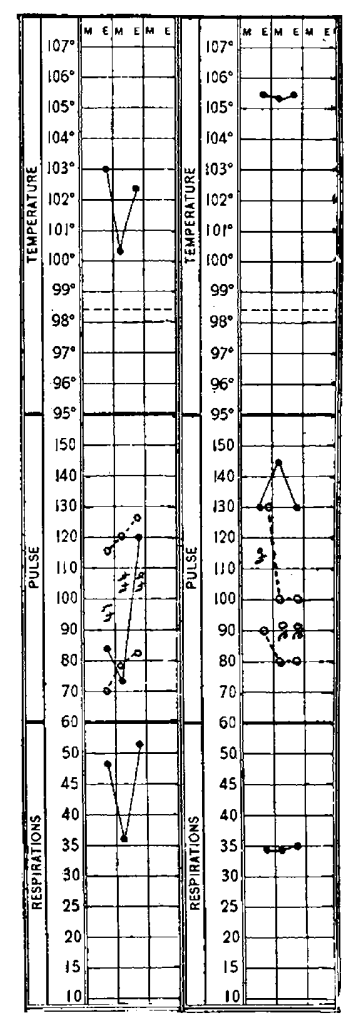

Fig. 2.-Charts of temperature, pulse and respiration in two fatal cases of pneumonia, showing that death may occur with a small or a large pulse-pressure and with a rising or falling systolic pressure, with a systolic pressure above or below the pulse. The lines of circles and dashes represent systolic and diastolic blood-pressure respectively.

as that employed for making Figure 1. Figure 3 shows the two curves. It will be noted that the curves of systolic pressure in both Figure 1 and Figure 3 lead to the same conclusions, that the systolic pressure in fatal cases tends to be higher than it is in the recoveries.

The working of Gibson's rule in these Johns Hopkins cases is as follows: 
Among 14 fatal cases, 6 followed the rule, 4 were doubtful, 4 did not follow the rule, that is, the rule held 6 times out of 14 (43 per cent.).

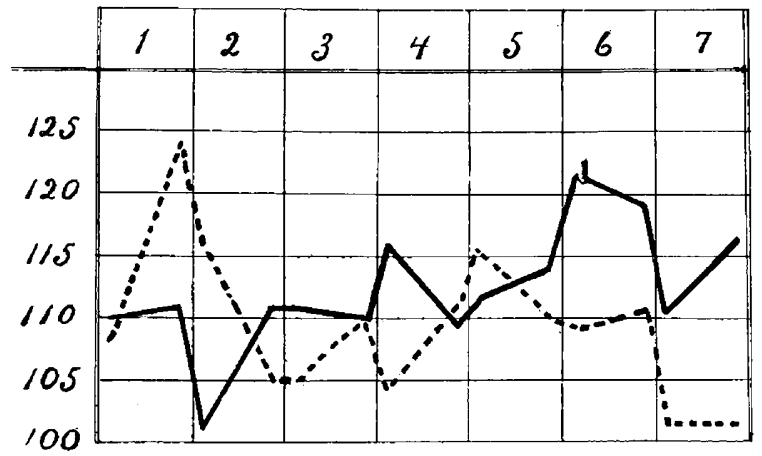

Fig. 3.-Curves of systolic pressure of fourteen fatal cases of pneumonia compared with sixteen recoveries taken from the records of the Johns Hopkins Hospital. Figure 3 was constructed in the same way as Figure 1.

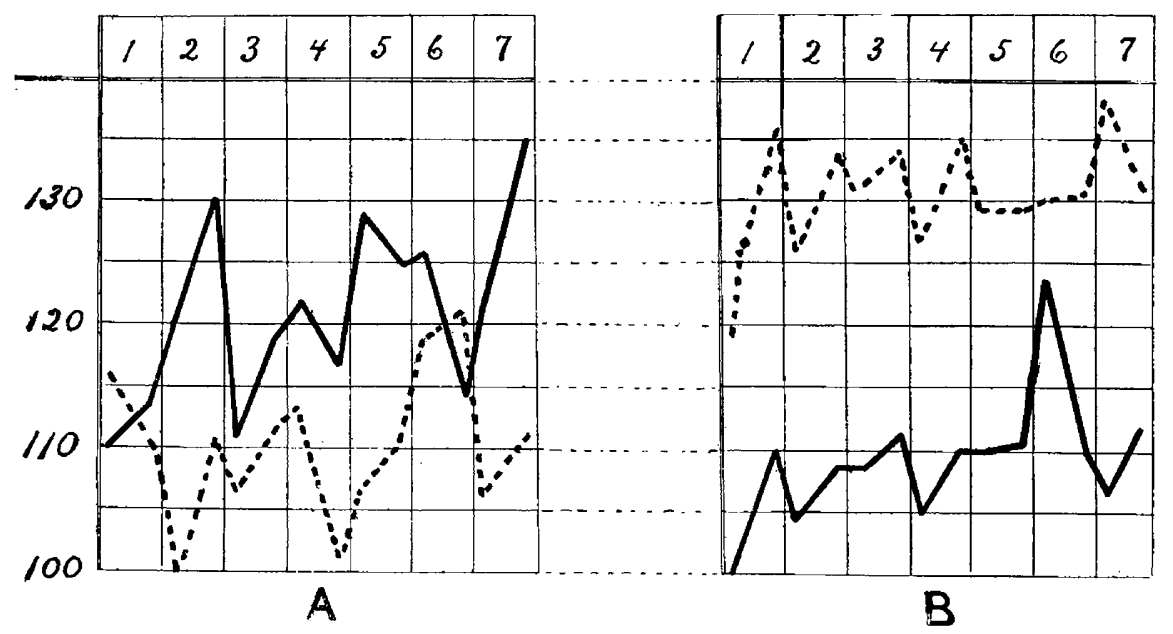

Fig. 4.-A: The solid line is the curve of systolic pressure in six fatal cases of pneumonia in which the systolic pressure was above the pulse. The broken line is the curve of systolic pressure in eight fatal cases in which the systolic pressure was below the pulse. B: The solid line represents the pulse rate in the same six fatal cases in which the systolic pressure is represented in A. The broken line is the pulse rate in eight fatal cases in which the systolic pressure is represented by the broken line in $\mathrm{A}$.

Among 16 recoveries 6 followed the rule, 2 were doubtful, 8 did not follow the rule, that is, the rule held 6 times out of 16 ( 37 per cent.).

In both groups the rule held only in a minority of the cases and was definitely wrong 40 per cent of the time. 
Lastly all the fatal cases (those of the Johns Hopkins Hospital and those of the Massachusetts General Hospital) have been divided into two groups with regard to the relation of the systolic pressure to the pulse. The first group includes the cases in which the systolic pressure expressed in millimeters of mercury fell above the pulse expressed in beats per minute. The second group includes the cases in which the systolic pressure fell below the pulse. In the first group there are eight cases, in the second, eight cases.

Figure 4 shows the relation of the pressures and the pulses in the two groups. It will be seen that the pressure curves fall very much closer together than the pulse curves. This immediately suggests that the rate of the pulse and not the level of the pressure, is the chief factor in deciding whether the pressure will fall above or below the pulse. That such is actually the fact can easily be determined by comparing the averages of all the measurements used in constructing each curve. By so doing, it is found that the average of the systolic pressures for the first group is 121, for the second group, 109, a difference of 11 ; whereas the averages for the pulses in the first group and second group are respectively 131 and 109, a difference of 22 . The rate of the pulse is exactly twice as important as the height of the systolic pressure in determining whether the latter shall fall above the former or vice versa.

SUMMARY

1. The blood-pressure curve does not suggest that there is a failure of the vasomotor center in pneumonia.

2. Low systolic pressures are not "invariably of evil omen."

3. The systolic pressure in these fatal cases tends to be higher than it is in the recoveries.

4. Blood-pressure measurements in pneumonia cannot be used as a basis for treatment.

5. Prognostic inferences based on the relation of the level of the systolic pressure curve to the pulse curve (Gibson's rule) are wrong more often than they are right in this series.

6. The rate of the pulse and not the level of the pressure is the chief factor in deciding whether the pressure will fall above or below the pulse.

7. The pulse-pressure data are insufficient in number to justify conclusions.

329 Beacon Street. 